\title{
Screening Moringa species focused on development of locally available sustainable nutritional supplements
}

\author{
Ye-Jung $\mathrm{Kim}^{1}$ and Hee Seon $\mathrm{Kim}^{2 \S}$ \\ ${ }^{1}$ HAITAI Confectionery \& Foods Co.,LTD, 3, Hangang-daero 72-gil, Yongsan-gu, Seoul 04352, Korea \\ ${ }^{2}$ Department of Food Science and Nutrition, Soonchunhyang University, 22 Soonchunhyang-ro, Shinchang-myun, Asan, Chungnam 31538, Korea
}

BACKGROUND/OBJECTIVES: The leaves of Moringa oleifera (MO) and Moringa stenopetala (MS) commonly grown in Ethiopia possess potential nutritional and medicinal value. The aim of this study was to evaluate the nutritional and functional characteristics of the dried leaf powder from two Moringa species to develop sustainable nutritional supplements for Ethiopians from locally grown plant sources.

MATERIALS/METHODS: Freshly harvested and air-dried MO and MS leaves were authenticated and the nutritional contents, such as protein, ash, lipids, and selected vitamins and minerals, were analyzed using standard analytical procedures. Amino acid compositions were also determined by an amino acid analyzer. Nine-week-old mice were randomly divided into four groups to investigate the anti-obesity effects of Moringa. The first group was fed a basal diet, the second group a high-fat diet, and the others were fed a high-fat diet containing $0.1 \%$ Moringa leaf powder from each species. After seven weeks, serum indices related to lipid profiles from each mouse were analyzed.

RESULTS: The present study revealed high protein (28-29\%) and ash (7-11\%) contents. Glutamic acid, aspartic acid, proline, and leucine were the most abundantly found amino acids in both species. The predominant minerals in the leaf powder were calcium (826-1,530 mg/100 g), potassium (794-904 mg/100 g), and magnesium (286-431 mg/100 g). Pyridoxine (475.06 $\mathrm{mg} / 100 \mathrm{~g})$ and vitamin E $(34.2 \mathrm{mg} / 100 \mathrm{~g})$ were found only in MS. Niacin was found only in MO at $32.21 \mathrm{mg} / 100 \mathrm{~g}$, whereas ascorbic acid was found in both species (3.89 and $6.19 \mathrm{mg} / 100 \mathrm{~g}$ dry weight for MO and MS, respectively). The results of the animal study showed that mice on a high-fat diet containing $0.1 \%$ MO leaf powder alleviated the elevation of cholesterol, triglycerides, and low-density lipoprotein cholesterol induced by the high fat diet. MO was more effective than MS in preventing hypercholesterolemia and fat deposition.

CONCLUSION: The findings in this work confirmed that Moringa leaves of both MO and MS possessed high nutritional value but $\mathrm{MO}$ was better at preventing the harmful effects of the high-fat diet than MS.

Nutrition Research and Practice 2019;13(6):529-534; https://doi.org/10.4162/nrp.2019.13.6.529; pISSN 1976-1457 elSSN 2005-6168

Keywords: Moringa oleifera, Moringa stenopetela, anti-obesity, serum lipid profile, nutritional value

\section{INTRODUCTION}

Family Moringaceae is represented by a single genus Moringa. The genus Moringa is represented by 14 different species, two of which are Moringa oleifera (MO) and Moringa stenopetala (MS). Moringa species, especially MO, is well known as an important multi-purpose crop in Africa and India. The species are now grown around the world. In contrast, MS is endemic only to northeast tropical Africa. The indigenous use of this specific species is mainly confined to southern Ethiopia and northern Kenya. Therefore, MO, which has a relatively larger distribution than MS that grows mainly in Ethiopia, has been studied more for its nutritional value, functional pharmacological effects, and efficacy as an alternative food [1-5] whereas, studies on MS have included nutrient analysis, analysis of pharmacological function, and cytotoxicity studies [6-8].

Despite an expected increase in food demand, many developing countries are still suffering from food insecurity. Especially in Ethiopia, food shortages and rural poverty have become chronic problems [9]. Since Moringa species are known as good nutrition sources and because they are highly tolerant of very dry conditions, they are often used as important famine foods, especially for infants and nursing mothers [10]. In addition, the fresh leaves of MS are cooked and eaten as a vegetable in Southern Ethiopia [6]. Moreover, the MS leaves are widely used as a traditional herbal remedy by the local population [11].

In many developing countries including Ethiopia, nutritional double burden and low food security have become an undesirable combination of an increasing and long-lasting serious health problem. Concerns regarding the imbalance between

\footnotetext{
This work was supported by a research grant from Soonchunhyang University.

${ }^{\S}$ Corresponding Author: Hee Seon Kim, Tel. 82-41-530-1263, Fax. 82-41-530-1264, Email. hskim1@sch.ac.kr

Received: September 9, 2019, Revised: September 23, 2019, Accepted: October 6, 2019

This is an Open Access article distributed under the terms of the Creative Commons Attribution Non-Commercial License (http://creativecommons.org/licenses/by-nc/3.0/) which permits unrestricted non-commercial use, distribution, and reproduction in any medium, provided the original work is properly cited.
} 
energy nutrient intake and micro-nutrient intake are now increasing in both developing and developed countries. Therefore, nutritional problems such as obesity and malnutrition, which appear both in food-rich and food-shortage regions in Ethiopia, are serious.

Although there is a consensus regarding the diverse biological activity of the different parts of plants in the family Moringaceae, there are conflicting reports as to their safety [12]. Considering the widespread use of MS as a food and medicinal plant in Ethiopia, and the published evidence of diverse biological activities of extracts (including cytotoxicity) from different parts of a related species (MO), MS needs to be investigated more thoroughly. Therefore, this study was conducted to determine whether MS was suitable for use in nutritional supplements in regions of Ethiopia by comparing its effects with those of MO. In the present study, only the leaf parts were examined since they are the most used and easily obtained part.

\section{MATERIALS AND METHODS}

Plant materials and preparation of dried leaf samples

Fresh leaves of MO and MS were collected from various regions of southern Ethiopia during 2011. The leaves were identified and authenticated at the National Herbarium of Addis Ababa, Ethiopia. Fresh moringa leaves were air-dried right after collection, then ground into a fine powder using a hammer mill. The powder was stored in a dry place in the dark at the Food Science and Nutrition Program at Addis Ababa University under accession number YA-03-2011. The plant powders were then transferred to South Korea in collaboration with KoreaEthiopia Science and Technology Research and stored at $-70^{\circ} \mathrm{C}$ until use.

\section{Analyses of selected nutrients}

The crude protein contents in the dried MO and MS samples were determined using the micro-Kjeldahl method. Ash contents were determined by incineration of the sample at $550^{\circ} \mathrm{C}$ for 6 hours. Mineral contents were determined using ICP-AES (Shimadzu ICPE-9000, Japan) after digesting $0.2 \mathrm{~g}$ of each sample in a microwave digestion system. The amino acids were analyzed by the methods of Lee et al. [13] using an amino acid analyzer (Sykam S430, Germany). Vitamin C and E were measured as described by $\mathrm{Kim}$ et al. [14]. Vitamins $B_{1}$, niacin, and pyridoxine were analyzed according to the 2012 Korean Food Standards Codex.

\section{Experimental animals}

Twenty 9-week-old male C57BL/6J mice were purchased from the OrientBio (Sungnam, Korea). Only male mice were selected for this research since one of the objectives was to determine changes in fat metabolism following Moringa ingestion and fat metabolism can be influenced by gender. The mice were housed in an air-conditioned animal room with a 12/12 h light/darkcycle at $22 \pm 2^{\circ} \mathrm{C}$, a relative humidity of $50 \pm 5 \%$, and free access to tap water and food ad libitum. The animals were adapted to these conditions for a week. After the acclimatization period, the mice were randomly divided into four groups of normal
Table 1. Composition of the experimental diets $(\mathrm{g} / \mathrm{Kg})$

\begin{tabular}{lccc}
\hline \multicolumn{1}{c}{ Ingredients (\%) } & $\begin{array}{c}\text { Basal diet } \\
(\text { ND) }\end{array}$ & $\begin{array}{c}\text { High-fat diet } \\
\text { (HF) }\end{array}$ & $\begin{array}{c}\text { High-fat diet + MO or } \\
\text { MS leaf powder }\end{array}$ \\
\hline Casein & 200 & 267 & 267 \\
Mineral mixture & 35 & 47 & 47 \\
Vitamin mixture & 10 & 13 & 13 \\
Dextrose & 132 & 176 & 176 \\
Cellulose & 50 & 67 & 67 \\
Soybean oil & 70 & 33 & 33 \\
Lard & 0 & 327 & 327 \\
Cornstarch & 397.5 & 63.4 & 63.4 \\
Sucrose & 10 & 0 & 0 \\
TBHQ & & 0.018 & 0.018 \\
L-cytine & 0.014 & 4 & 4 \\
Choline bitartrate & 2.5 & 3.3 & 3.3 \\
Moringa leaf powder & 0 & 0 & 1 \\
\hline
\end{tabular}

1) Tert-Butylhydroquione

diet (ND), high-fat diet (HD), high-fat diet with $1 \%$ MO leaf powder (HDMO), and high-fat diet with $1 \%$ MS leaf powder (HDMS) group containing five mice each. All animals were separately fed their corresponding diets for seven weeks. The normal diet and high-fat diet were purchased from FEEDLAB in Guri-si, Gyeonggi, Korea. The experimental diets of the HDMO and HDMS groups were prepared by adding $1 \mathrm{~g}$ of MO or MS leaf powder to $1 \mathrm{~kg}$ of purchased high-fat diet. The composition of the diets is shown in Table 1.

The animal study was conducted to minimize pain or discomfort and all appropriate precautions regarding the care and use of animals for experimental procedures were taken. The study was approved by the Institutional Animal Ethics Committee at Soonchunhyang University (SCH13_01_01).

Measurement of body weight, food intake, and food efficiency ratio

The bodyweight of all mice was determined just before the initiation of experimental feeding and every week for seven weeks thereafter using a digital balance. The amount of food intake was calculated on a per cage basis and expressed as the grams of food per day. The food efficiency ratio was calculated by (daily weight gain/daily food intake) $\times 100$.

Serum collection and histological sample preparation

Blood samples were collected from the retro-orbital plexus vein of all mice after fasting overnight (more than $12 \mathrm{~h}$ ). The blood samples were kept for about half an hour at room temperature before centrifugation at 3,000 rpm for $10 \mathrm{~min}$ to separate the serum for examination. The serum was separated and stored at $-70^{\circ} \mathrm{C}$ for analysis. Then, the animals were anesthetized and euthanized. The liver was quickly removed and washed with ice-cold saline to remove the blood and dried between filter paper. The liver tissues were immersed for 48 $\mathrm{h}$ at $4^{\circ} \mathrm{C}$ in fixative solution (4\% formaldehyde in phosphate buffer, $\mathrm{pH}$ 7.6), dehydrated in an ascending graded series of ethanol, embedded in paraffin, and stained with hematoxylineosin solution (H\&E). The tissue preparations were observed and microphotographed under a light microscope (Primovert Axio Imager, ZEISS, Germany). 
The serum albumin and glucose concentrations were analyzed by a commercial laboratory (NEODINE Vet Lab, Seoul, Korea). Total cholesterol (TC), triglycerides (TG), and low-density lipoprotein cholesterol (LDL-C) were determined using kits obtained from Asan Pharm. Co., Ltd. (Seoul, Korea). High-density lipoprotein cholesterol (HDL-C) was calculated according to the Friedewald formula.

\section{Statistical analyses}

The chemical and biochemical determinations were carried out in triplicate. The results are expressed as mean \pm standard deviation (SD) and were subjected to two-way analysis of variance (ANOVA). The data were analyzed using Duncan's Multiple Range Test. Statistical significance was determined at $P<0.05$. Statistical analyses were performed using SPSS software version 23 for Windows.

\section{RESULTS}

\section{Nutritional values}

Table 2 depicts the approximate dry weight composition of the MO and MS leaves. The MO and MS leaves contained crude

Table 2. Nutrient composition of dried MO and MS leaves

\begin{tabular}{|c|c|c|}
\hline & Moringa oleifera & Moringa stenopetala \\
\hline & \multicolumn{2}{|c|}{$\% \mathrm{DM}$} \\
\hline Crude protein & $28.21 \pm 0.25$ & $29.43 \pm 0.11$ \\
\hline Crude fat & $6.04 \pm 0.28$ & $7.21 \pm 0.18$ \\
\hline Ash & $7.10 \pm 0.02$ & $11.59 \pm 0.01$ \\
\hline $\mathrm{Ca}$ & $826 \pm 7.55$ & $1530 \pm 43.59$ \\
\hline K & $794.33 \pm 62.07$ & $904 \pm 25.94$ \\
\hline $\mathrm{Mg}$ & $286 \pm 22.61$ & $431.33 \pm 8.74$ \\
\hline $\mathrm{P}$ & $362.5 \pm 17.78$ & $268.5 \pm 10.21$ \\
\hline $\mathrm{Na}$ & $102.1 \pm 6.94$ & $128.87 \pm 0.49$ \\
\hline $\mathrm{Fe}$ & $16.85 \pm 0.80$ & $19.53 \pm 2.35$ \\
\hline Se & $4.01 \pm 0.15$ & $5.23 \pm 0.10$ \\
\hline $\mathrm{Zn}$ & $1.92 \pm 0.10$ & $2.29 \pm 0.14$ \\
\hline \multirow[t]{2}{*}{$\mathrm{Cu}$} & $0.69 \pm 0.02$ & $0.57 \pm 0.16$ \\
\hline & \multicolumn{2}{|c|}{$\mathrm{mg} / 100 \mathrm{~g} \mathrm{DM}$} \\
\hline Vitamin C & $3.89 \pm 0.42$ & $6.19 \pm 0.57$ \\
\hline Vitamin E & - & $34.21 \pm 0.87$ \\
\hline Thiamin & - & - \\
\hline Pyridoxine & $302.42 \pm 1.21$ & $475.06 \pm 2.54$ \\
\hline Niacin & $32.21 \pm 1.79$ & \\
\hline
\end{tabular}

DM: dry matter of tissue protein (28.28 and 29.47\%), crude fat (6.04 and 7.21\%), and ash (7.10 and $11.59 \%$, respectively). Calcium was present in the highest concentration in both $\mathrm{MO}$ and MS. Other essential minerals, such as potassium and magnesium, were also present in both MO and MS. All minerals analyzed were higher in MS than in MO, except for phosphorus and copper.

Selected vitamin concentrations are reported in Table 2. MO contained $3.89 \mathrm{mg} / 100 \mathrm{~g}$ vitamin C, $302.4 \mathrm{mg} / 100 \mathrm{~g}$ pyridoxine, and $32.2 \mathrm{mg} / 100 \mathrm{~g}$ niacin, whereas MS contained $6.19 \mathrm{mg} / 100$ $\mathrm{g}$ vitamin C, $475.1 \mathrm{mg} / 100 \mathrm{~g}$ pyridoxine, and $34.2 \mathrm{mg} / 100 \mathrm{~g}$ vitamin $\mathrm{E}$. Among the vitamins analyzed, niacin was found only in $\mathrm{MO}$ and vitamin $\mathrm{E}$ was found only in $\mathrm{MS}$ and vitamin $\mathrm{B}_{1}$ was not detected in either MO or MS.

The amino acid composition of the dried MO and MS leaves is presented in Table 3 . Among 20 proteinogenic amino acids, 17 amino acids, including nine essential amino acids, were analyzed. Glutamic acid, proline, and aspartic acid were the predominant amino acids in both MO and MS. The order of the essential amino acids concentrations were leucine, phenylalanine, lysine, threonine, valine, histidine, isoleucine, histidine,

Table 3. Amino acid composition of dried Moringa oleifera and Moringa stenopetala leaves

\begin{tabular}{llcc}
\hline & & Moringa oleifera & Moringa stenopetala \\
\hline \multirow{2}{*}{ EAA $\quad$ Histidine } & $0.35 \pm 0.03$ & $0.33 \pm 0.02$ \\
& Leucine & $1.43 \pm 0.12$ & $1.26 \pm 0.11$ \\
& Isoleucine & $0.65 \pm 0.04$ & $0.55 \pm 0.07$ \\
& Lysine & $0.95 \pm 0.03$ & $0.86 \pm 0.04$ \\
Methionine & $0.24 \pm 0.01$ & $0.21 \pm 0.01$ \\
Phenylalanine & $1.05 \pm 0.04$ & $0.91 \pm 0.05$ \\
Threonine & $0.85 \pm 0.02$ & $0.79 \pm 0.03$ \\
Valine & $0.83 \pm 0.03$ & $0.72 \pm 0.04$ \\
NEAA & & $\%$ DM & \\
Alanine & $1.18 \pm 0.04$ & $1.01 \pm 0.02$ \\
Arginine & $0.98 \pm 0.04$ & $1.03 \pm 0.04$ \\
Aspartic acid & $1.74 \pm 0.07$ & $2.16 \pm 0.09$ \\
Cysteine & $0.21 \pm 0.02$ & $0.26 \pm 0.02$ \\
Glutamic acid & $2.38 \pm 0.09$ & $1.90 \pm 0.18$ \\
Glycine & $0.86 \pm 0.02$ & $0.79 \pm 0.04$ \\
Proline & $1.86 \pm 0.10$ & $1.48 \pm 0.16$ \\
Serine & $0.91 \pm 0.07$ & $0.89 \pm 0.06$ \\
Tyrosine & $0.66 \pm 0.01$ & $0.61 \pm 0.02$ \\
\hline Total & 17,130 & 15,760 \\
\hline
\end{tabular}

DM, dry matter of tissue; EAA, essential amino acids; NEAA, non-essential amino acids.

Table 4. Serum lipid profile, glucose and albumin concentrations of mice fed experimental diets for 7 weeks.

\begin{tabular}{|c|c|c|c|c|}
\hline & ND & $\mathrm{HD}$ & $\mathrm{HDMO}$ & HDMS \\
\hline Albumin & $6.47 \pm 1.36$ & $4.33 \pm 0.42$ & $4.86 \pm 0.12$ & $5.23 \pm 0.25$ \\
\hline Glucose & $183.33 \pm 62.43^{\mathrm{a}}$ & $358.00 \pm 15.87^{b}$ & $264.33 \pm 87.32^{\mathrm{ab}}$ & $314.81 \pm 41.25^{\mathrm{ab}}$ \\
\hline Triglyceride & $82.67 \pm 18.03$ & $92.00 \pm 14.00$ & $60.00 \pm 14.00$ & $87.00 \pm 24.43$ \\
\hline Total cholesterol & $110.67 \pm 21.21^{a}$ & $181.33 \pm 21.22^{b}$ & $118.00 \pm 40.15^{\mathrm{a}}$ & $140.59 \pm 35.81^{\mathrm{ab}}$ \\
\hline HDL-cholesterol & $29.06 \pm 4.38$ & $21.80 \pm 10.32$ & $17.20 \pm 11.03$ & $21.40 \pm 19.60$ \\
\hline LDL-cholesterol & $65.05 \pm 14.38^{\mathrm{a}}$ & $142.52 \pm 12.81^{b}$ & $88.83 \pm 31.05^{\mathrm{ab}}$ & $107.52 \pm 12.41^{\mathrm{ab}}$ \\
\hline
\end{tabular}

$\mathrm{ND}$, normal diet; $\mathrm{HD}$, high-fat diet; $\mathrm{HDMO}$, high-fat diet with $1 \% \mathrm{MO}$; HDMS, high-fat diet with $1 \% \mathrm{MS}$.

Values with different superscript letters in each row are statistically different at $P<0.05$ by ANOVA and Duncan's multiple range post-hoc tests. 
and methionine, however, the concentrations in MS were higher than in $\mathrm{MO}$.

\section{Results of the animal experiments}

Fig. 1 shows the weight gain of the mice during the experimental period. Body weight in the HD group was significantly higher compared to the ND, HDMO, and HDMS groups $(P<$ 0.05) (Fig. 1A). The average daily food intake was significantly lower in the HD and HDMO groups compared to the ND group. However, there was no significant difference in the food intake of the HDMS group compared to ND (Fig. 1B). The food efficiency ratio of the HD and HDMO were significantly higher than that of the ND group. There was no difference in the food efficiency ratio between the HDMS group and the ND and HD groups.
The serum albumin, triglyceride and HDL-cholesterol levels of the mice from four experimental groups did not show any statistical differences (Table 4). The results of the serum glucose and LDL- cholesterol levels showed that HD groups showed the higher levels than ND group while HDMO and HDMS groups were in between ND and HD. The serum total cholesterol levels of ND and HDMO groups were lower than that of HD group whereas this was not seen in the HDMS mice. The liver sections of control mice in the ND group revealed normal tissue morphology of the hepatic cells and sinusoids (Fig. 2A). However, the livers of the HD animals revealed histopathological damage. The HD group showed lipid droplet accumulation, marked vein congestion, and hepatocyte degeneration (Fig. 2B). These alterations were attenuated in the HDMO and HDMS groups (Fig. $2 \mathrm{C}$ and 2D).
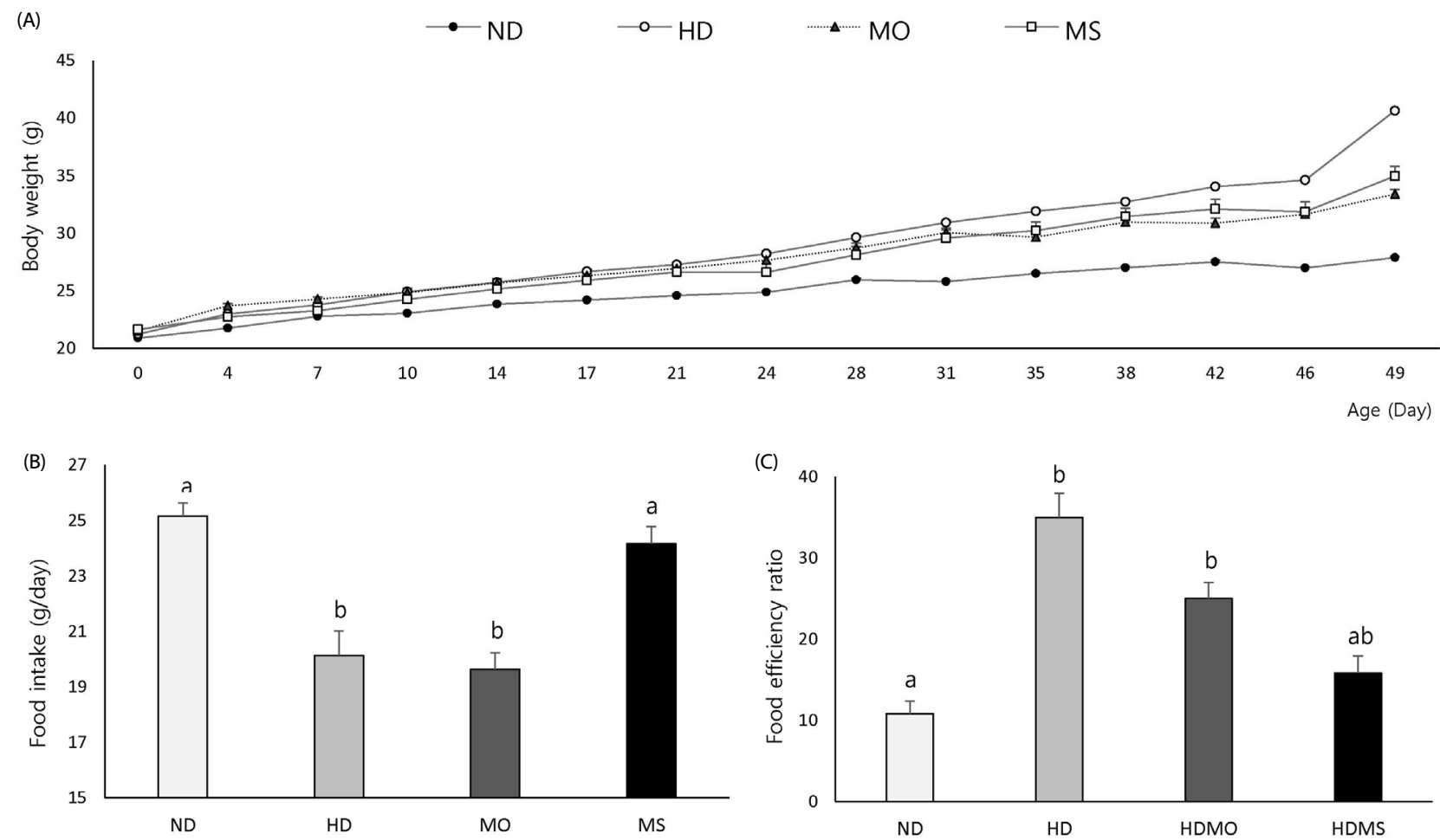

Fig. 1. Effects of $M O$ and $M S$ on (A) body weight, (B) food intake, and (C) the food efficiency ratio in mice fed high-fat diet. ND, normal diet; $H D$, high-fat diet; HDMO, high-fat diet with $1 \%$ MO; HDMS, high-fat diet with $1 \%$ MS. The food efficiency ratio is calculated by (daily weight gain/ daily food intake) $\times 100$. Values are expressed as mean \pm SEM $(n=5)$. Values with different letters are statistically different at $P<0.05$ by ANOVA and Duncan's multiple range post-hoc tests

(A)

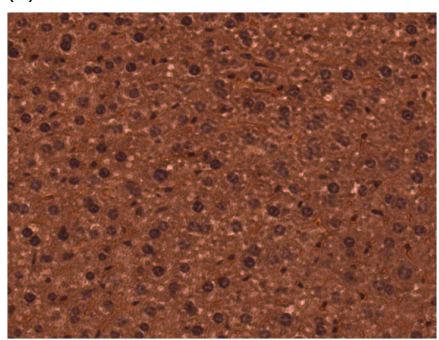

(B)

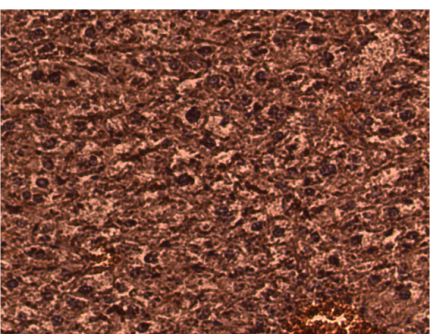

(C)

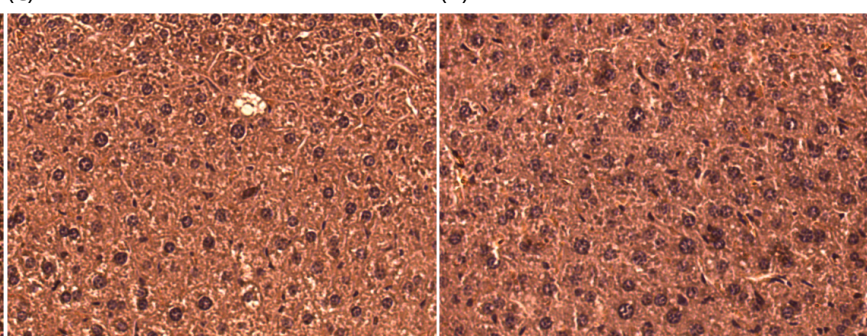

Fig. 2. Microscopic images of mice liver sections (A, B, C, and D: 100x). (A) Control group (normal diet group) showing normal hepatic structure. (B) High-fat diet group showing fatty deposition, cellular degeneration, and central vein congestion. (C) High-fat diet group with $1 \%$ MO leaves. (D) High-fat diet group with 1\% MS leaves. The liver sections were stained with hematoxylin-eosin. 


\section{DISCUSSION}

The study confirmed that both MO and MS Moringa species were good sources of nutrients. As expected, dried Moringa leaves showed high protein content. In our study, the high protein content was composed of a vast diversity of amino acids. Both the MO and MS dried Moringa leaves contained all 17 amino acids analyzed, including the eight essential amino acids (histidine, valine, methionine, isoleucine, leucine, phenylalanine, lysine, and threonine). Unfortunately, tryptophan was not analyzed due to a technical problem. Concentrations of the essential amino acids were found in the order of leucine, phenylalanine, lysine, threonine, valine, histidine, isoleucine, histidine, and methionine.

Other studies reported that dried MO leaves contained 16 or 17 amino acids $[15,16]$. Methionine, cysteine, histidine, tyrosine, and isoleucine were present in moderate concentrations (0.21$0.66 \%$ ) in our study. However, these limited amino acids were reported to be the most abundant in other studies [15]. Previous studies strongly suggested that MO may be an important source of vitamins [17]. The vitamins analyzed in MO and MS showed different patterns between the species. Vitamin E was only detected in MS in our study, whereas other researchers reported considerable amounts of vitamin E in MO [17]. Among the vitamins analyzed, vitamin $C$ and pyridoxine were found in both species, however, they were higher in MS than in MO and niacin was found only in MO. Vitamin $B_{1}$ was not detected in either $\mathrm{MO}$ or MS, unlike another study that reported finding vitamin $B_{1}$ in various parts of $M O$ [17]. Discrepancies in the amino acid compositions and other nutrient values can be due to external conditions, such as climate, soil type, and fertility. External conditions subsequently affect the protein quality and the nutritional value of the sample [18].

Calcium levels appear to be the most significant mineral present in both MO and MS. Other essential minerals as potassium and magnesium were also remarkably present in both MO and MS. Among the nutritive significance of MO leaves is their rich mineral content, essential for the maintenance of human health and MS was confirmed to have the same effect with the higher content.

Not all nutrients were analyzed. Nevertheless, it is hard to determine which species was more nutritious. However, since MO and MS are very common plants in Ethiopia, and large quantities are available at any time, there seems to be no shortage of local raw materials available for developing nutritional supplements. In many countries in Africa, including Ethiopia, the imbalance between energy nutrient intake and micronutrient intake in poor, food-insecure environments and obesity and malnutrition in food-rich areas is a serious nutritional problem with a double burden. Moringa has long been used as a nutritional supplement for famine in Ethiopia [6], so this study was conducted to determine whether it was suitable for use in nutritional supplements. The results of the nutritional analyses were encouraging. Due to the serious double burden problems, we assumed that MO and MS would supply micronutrients and prevent weight increases from high-fat diets, and the effects $\mathrm{MO}$ on fat metabolism in the body were confirmed positively.
The current research found that the MO diet prevented weight gain and increases in serum lipids associated with high-fat diets. However, the effects of MS were less than those of MO. Therefore, the results of this study showed that $\mathrm{MO}$ and MS can be good raw materials when Moringa is used as a material for developing nutritional supplements using local plants. However, the anticipated protective effect against high-fat diets was seen for MO, but the effect of MS was not as great.

In conclusion, MO and MS both had high nutrient contents, so can be used to develop nutritional supplements, not only in Ethiopia but also in Africa and Southeast Asia where Moringa is abundant. In particular, since MO has anti-obesity effects, both micronutrients and anti-obesity effects can be expected from MO supplementation in developing countries suffering from nutritional double burden. Although MS has nutritional value as a good vitamin and mineral source, the development of nutritional supplements using MS should be approached with caution due to its toxic effect [12]. Therefore, safety tests must be conducted on MS in the future.

\section{ACKNOWLEDGEMENTS}

The authors would like to express their deepest appreciation to the faculty of Addis Ababa University for their efforts in collecting and transferring the plant specimens.

\section{CONFLICT OF INTEREST}

The authors declare no potential conflicts of interests.

\section{ORCID}

Ye-Jung Kim: https://orcid.org/0000-0003-2091-3758

Hee Seon Kim: https://orcid.org/0000-0001-7235-2644

\section{REFERENCES}

1. Rockwood JL, Anderson BG, Casamatta DA. Potential uses of Moringa oleifera and an examination of antibiotic efficacy conferred by $M$. oleifera seed and leaf extracts using crude extraction techniques available to underserved indigenous populations. Int J Photother Res 2013;3:61-71.

2. Falowo $A B$, Mukumbo $F E$, Idamokoro EM, Lorenzo JM, Afolayan $A J$, Muchenje V. Multi-functional application of Moringa oleifera Lam. in nutrition and animal food products: a review. Food Res Int 2018;106:317-34.

3. Bamishaiye El, Olayemi FF, Awagu EF, Bamshaiye OM. Proximate and phytochemical composition of Moringa oleifera leaves at three stages of maturation. Adv J Food Sci Technol 2011;3:233-7.

4. Saini RK, Manoj $P$, Shetty NP, Srinivasan K, Giridhar, P. Dietary iron supplements and Moringa oleifera leaves influence the liver hepcidin messenger RNA expression and biochemical indices of iron status in rats. Nutr Res 2014;34:630-8

5. Gopalakrishnan L, Doriya K, Kumar DS. Moringa oleifera: a review on nutritive importance and its medicinal application. Food Sci Hum Wellness 2016;5:49-56.

6. Yisehak K, Solomon M, Tadelle M. Contribution of Moringa (Moringa 
stenopetala, Bac.), a highly nutritious vegetable tree, for food security in South Ethiopia: a review. Asian J Appl Sci 2011;4:477-88.

7. Tenaye A, Geta E, Hebana E. A multipurpose cabbage tree (Moringa stenopetala): Production, utilization and marketing in SNNPR, Ethiopia. Acta Hortic 2009:115-20.

8. Jiru D, Sonder K, Alenayehu L, Mekonen Y, Anjulo A. Leaf yield and nutritive value of Moringa stenopetala and Moringa oleifera accessions: its potential role in food security in constrained dry farming agroforestry system. Proceedings of Moringa and other Highly Nutritious Plant Resources: Strategies, Standards and Markets for a Better Impact on Nutrition in Africa; 2006 Nov 16-18; Accra, Ghana. Daily digest Moringa workshop. Accra, Ghana.

9. Kebebe E, Sheleme B, Wondimu W. Learning experiences of farmers field school on integrated nutrient management: evidence from Wolaita in Southern Ethiopia. J Agron 2007;6:560-5

10. Mahmood KT, Mugal T, Haq IU. Moringa oleifera: a natural gift A review. J Pharm Sci Res 2010;2:775-81.

11. Mark EO. Research on applied uses of Moringa stenopetala. FAO Technical Bulletin No. 4-4. Rome, Italy: FAO; 1998. Available from: http://www.berfingen.info/akababi/simon.htm.

12. Mekonnen $\mathrm{N}$, Houghton $\mathrm{P}$, Timbrell J. The toxicity of extracts of plant parts of Moringa stenopetala in HEPG2 cells in vitro. Phytother Res 2005;19:870-5.

13. Lee KA, Kim YJ, Koh K, Kim HS. Nutrient analyses of sustainable ready-to-use supplemental food (RUSF) developed with East African ethnic plant resources. J East Asian Soc Diet Life 2016;26:466-72.

14. Koh K, Kim YJ, Kim HS. Nutrition analyses of nutrition bar cooked with a solar box-cooker. Korean J Hum Ecol 2016;25:487-95.

15. Olaofe O, Adeyeye El, Ojugbo S. Comparative study of proximate, amino acids and fatty acids of Moringa oleifera tree. Elixir Appl Chem 2013;54:12543-54.

16. Spackman DH, Stein WH, Moore S. Chromatography of amino acids on sulphonated polystyrene resins: an improved system. Anal Chem 1958;30:1190-205.

17. ljarotimi OS, Adeoti OA, Ariyo O. Comparative study on nutrient composition, phytochemical, and functional characteristics of raw, germinated, and fermented Moringa oleifera seed flour. Food Sci Nutr 2013;1: 452-63.

18. Förster N, Ulrichs C, Schreiner M, Arndt N, Schmidt R, Mewis I. Ecotype variability in growth and secondary metabolite profile in Moringa oleifera: impact of sulfur and water availability. J Agric Food Chem 2015;63:2852-61. 